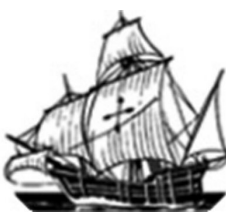

\title{
TAUTOLOGIA DA XILOGRAVURA DE CORDEL: ORALIDADE, TEXTO \\ E IMAGEM
}

\author{
Ênio Chaves Monteiro ${ }^{1}$ \\ Vera Pires ${ }^{2}$
}

RESUMO: A presente comunicação objetiva tecer reflexões a respeito da herança tautológica visual medieval, presente nas xilogravuras do cordel nordestino. A representação gráfica simples e os textos, muitas vezes rimados do cordel, são versões de figurações da idade média, preservadas pela igreja em forma de herança cultural, quando a mesma usava da iconoclastia cristã (seja ela pictórica, escultórica ou gráfica) para arrebanhar fiéis, tornando-a fonte de arrebatamento e para fazer tementes os iletrados. A xilogravura, como parte da poética literária nordestina, torna-se tautologia do texto escrito, transcendendo seu estatuto gráfico e recontando a história ali gravada, cativando leitores de menor fluência cultural. Além de subverter a condição estabelecida por uma sociedade desigual, que priva o acesso aos meios de comunicação escritos, essa xilogravura possui função originária instigadora da visualidade e da oralidade. A partir dos estudos, Idelette Muzart-Fonseca dos Santos, em Memória das Vozes: cantoria romanceiro e cordel (2006), a autora descreve como a técnica de se gravar imagens em relevo sobre madeira se transcreveu da Europa para o nordeste brasileiro, podendo-se tecer um histórico dessa linguagem. Galvão (2001) atenta que a força estética da ilustração das capas dos folhetos tem função não apenas de ilustrar, mas, também, de atrair o leitor dando pistas sobre o que vai ser tratado na obra. Tal força estética é fundamental para representar o texto de forma rápida revelando a importância da xilogravura como alvo de interesse pelos estudiosos da literatura.

Palavras chave: tautologia, imagem, texto, oralidade

RESUMEN: La presente comunicación tiene por objetivo exponer reflexiones al respecto de la herencia tautológica visual medieval, presente en los xilograbados del cordel nordestino. La representación gráfica simple y los textos, reiteradas veces rimados en el cordel, son versiones de figuraciones de la edad media, preservadas por la iglesia en forma de herencia cultural, cuando se empleaba la iconoclasía cristiana (fuese pictórica, escultórica o gráfica) para recaudar fieles, transformándolos en fuente de arrebatamiento y para atraer

Mestrando em Letras do Centro Universitário Ritter dos Reis - UNIRITTER. e22bolsa@yahoo.com.br. Endereço: Rua Orfanotrófio, 555, Alto Teresópolis, Porto Alegre, RS.

2 Doutora em Letras, Professora do Programa de Pós-Graduação em Letras do Centro Universitário Ritter dos Reis - UNIRITTER. Pires.veralu@gmail.com. Endereço: Rua Orfanotrófio, 555, Alto Teresópolis, Porto Alegre, RS. 
nuevos creyentes o iletrados. El xilograbado, como parte de la poética literaria nordestina, se transforma en tautología del texto escrito, transcendiendo su estatuto gráfico y recontando la historia grabada, cautivando lectores de menor fluencia cultural. Además de trastornar la condición establecida por una sociedad desigual, que privaba el acceso a los medios de comunicación escritos, ese xilograbado posee una función originaria instigadora de la visualidad y de la oralidad. A partir de los estudios, Idelette Muzart-Fonseca dos Santos, en Memória das Vozes: cantoria romanceiro e cordel (2006), la autora describe cómo la técnica de grabar imágenes en relieve sobre madera se transcribió de Europa para el nordeste brasileño, sobre el cual podemos delinear un histórico de lenguaje. Galvão (2001) destaca que la fuerza estética de la ilustración de las tapas de los folletos desempeña la función no apenas de ilustrar, pero, también, de atraer el lector dándole pistas sobre lo que será tratado en la obra. Tal fuerza estética es fundamental para representar el texto de forma rápida revelando la importancia del xilograbado como punto de interés por los estudiosos de la literatura.

Palabras clave: tautología, imagen, texto, oralidad

\section{Introdução}

A literatura de Cordel é por natureza uma literatura de migração, que tem na memória e na oralidade sua maior característica. Sua estrutura moderna é advinda diretamente do medieval europeu. Em Portugal, os livretos de cordel são chamados de folhas volantes, na Espanha chamam-na pliegos sueltos e na França litterature de Colportageraízes. Anteriormente conhecida como "livrinho de feira", "folheto", "folhinha", "poesias populares", "romance", foi assim nomeada no Brasil por estudiosos do assunto que criaram e difundiram o termo "literatura de cordel" por compreenderem, como explica Abreu (1999) seu aspecto físico relacionado a forma de comercialização (pendurados em cordas ou barbantes nas feiras). Essa nomeação foi facilmente aderida e em nada é resultante de cunho popular. Seu início em forma de livreto deu-se no século XVII na Europa, onde circulou até meados do século XIX, tornando-se rarefeita e extinguindo-se. Foi na época colonial que esse tipo de literatura aportou no Brasil. Mais especificamente no nordeste do país, onde o contato com a cultura africana Akpalô dos escravos e seu viés tipicamente oral a fizeram ganhar espaço e visibilidade, para pouco depois retomar seu formato material, impresso. A impressão dos cordéis, ao contrário de seu ancestral europeu, não possuía tanto detalhamento gráfico nem eram compostos por tipos moveis. Ao contrário, apropriou-se de tecnologia gráfica rudimentar. Consistia na impressão de placas simples de madeira como matrizes e tinham como suporte papel de baixa qualidade. Como é sabido, a língua oral, é econômica e tende à simplificação. Os livretos possuíam tamanho pequeno e poucas páginas. A quantidade rarefeita de páginas é uma característica marcante da linguagem do cordel. Essa condição técnica facilitou enormemente a transposição de histórias típicas da oralidade e folclore nordestino para o espaço reduzido do livreto, que também encontraram na forma de verso (contrária a sua versão européia em prosa) uma linha narrativa típica. A versificação é inerente a cultura oral que o cordel herdou. Sua estrutura versificada era consoante ao caráter 
performático do artista: cantava em repente seus textos, comumente acompanhado de viola ou rabeca (instrumento típico nordestino, herança cultural moura e ibérica). Sua comercialização, pendurados em varais ou dentro de malas (formas fáceis de carregar o produto) davam dinamicidade ao cordelista:

No Nordeste [...], por condições sociais e culturais peculiares, foi possível o surgimento da literatura de cordel, da maneira como se tornou hoje em dia característica da própria fisionomia cultural da região. Fatores de formação social contribuíram para isso; a organização da sociedade patriarcal, o surgimento de manifestações messiânicas, o aparecimento de bandos de cangaceiros ou bandidos, as secas periódicas provocando desequilíbrios econômicos e sociais, as lutas de família deram oportunidade, entre outros fatores, para que se verificasse o surgimento de grupos de cantadores como instrumentos do pensamento coletivo, das manifestações da memória popular. (DIÉGUES JR, 1986 apud GALVÃO, 2001, p. $31)$.

As raízes medievalescas do cordel nos trazem principalmente histórias que narram o duelo entre o "Bem" e o "Mal" e o nascimento do mito do herói. Histórias de reis em meio a guerras transformaram-se em mitos através do jogral, o bardo intinerante, o poeta do povo encarregado de difundir e divulgar os feitos dos heróis, que, conscientemente ou não, ajudava a fabricar enquanto viajava de cidade em cidade. Narrativas de cavalarias se transfiguraram para o contexto local nordestino. Primeiramente com grande influência de lendas e mitos locais atrelados a iconoclastia católica. Deve-se frisar que as condutas dos santos heróis (ou mesmo de Maria ou Jesus) são humanizadas e terrenas, possuindo relações diretas com os homens. Peter Burke (1989) afirma que o culto aos santos era generalizado em 1500 (época da chegada dos colonizadores ao Brasil), e alguns santos sobreviveram em áreas protestantes européias por muito tempo depois da reforma como figuras do folclore popular. Maior parte das histórias de heróis são advindas das mesmas fontes, apenas recontadas envoltas em outra roupagem. Seguindo a linha teórica de Burke (1989) pode-se afirmar que na cultura popular européia medieval como no cordel nordestino existem quatro tipos de heróis principais: o santo, o guerreiro, o governante e o fora da lei:

Em muitos casos, não é difícil ver como personagens que chegaram mais tarde a tradição vinham modelados segundo protótipos anteriores. São João Batista, por exemplo, era protótipo do asceta, vivendo no deserto, alimentado-se de gafanhotos e mel silvestre, usando uma "roupa de pelo de camelo" (Mateus, 3, 1-4), e outros ascetas como santo Antônio Abade ou são Humphrey (que deixou crescer cabelo e barba excepcionalmente longos) parecem seguir seu modelo. Alexandre, o Grande, era protótipo do governante vitorioso no exterior, assim como Salomão era modelo de governante sábio internamente. (p. 174)

No Brasil, pode-se tomar como exemplo de transformação a lenda de Dom Sebastião, rei português desaparecido em batalha de Alcácer-Quibir, no Marrocos, em 1578, que renderam aos cordelistas inspiradoras recontações do mito sebastianino em meio ao cenário 
agreste do nordeste brasileiro. Romances de cavalaria também deram origem aos cordéis sobre o cangaço onde, ao invés de senhores feudais e seus cavaleiros, enfrentavam uma burguesia latifundiária e seus comparsas.

\section{Tautologia imagética e alegoria de medievalidade}

A primeira instância de leitura/audição era o momento em que se percorriam as feiras e ouviam o vendedor em sua leitura competente, declamada ou cantada em voz alta, cortada no momento do clímax do enredo. Era o momento de curiosidade para saber qual seria o desfecho da narrativa. Galvão (2001) relata que depois de adquiridos ou tomados como emprestados, os folhetos eram geralmente lidos em grupo, em reuniões que congregavam grande quantidade de pessoas, na casa de vizinhos e familiares. Aquele que possuísse maior número e variedade de títulos de folhetos em casa chamava parente e amigos para, coletivamente, usufruírem das leituras. As imagens ali contidas podiam ser apreciadas por todos, desde crianças curiosas e ainda não alfabetizadas até adultos analfabetos, o que era e ainda é uma realidade comum no nordeste brasileiro. A xilogravura surge no cordel como uma forma de atingir o público não letrado. Suas matrizes de madeira (advinda do cajá, árvore frutífera abundante na região) foram base para a gravação de imagens de aspecto ingênuo (naï), visto seus produtores não possuírem formação e erudição acadêmicas, sendo impressas em sua maioria em preto e branco ou em poucas cores. A baixa escolaridade do leitor consumidor desse tipo literário forçou alguns cordelistas a tornar suas histórias ilustradas. As imagens passaram a cumprir função de iluminuras: são a representação imagética do que no texto está escrito ou cantado pelo repentista.

A xilogravura é uma técnica de gravação sobre madeira em um processo muito parecido com o do carimbo. Tem sua provável origem na china antiga e tornou-se comum na Europa medieval. Transplantou-se para o nordeste brasileiro (onde assumiu papel norteador estético e cultural). Na forma de símbolo, o próprio conceito é literalmente exposto no mundo matérico, e imageticamente o vemos, direta ou indiretamente. Assim, o simbólico é pautado pelo momentâneo; este falta ao alegórico, em que ocorre uma progressão lenta em uma série de momentos. Hansen (2011) afirma que historicamente os romanos viam a alegroria como ornamentação de discursos produzidos numa prática forense e poética, regidas por preceitos convencionados evidenciando justamente seu caráter particular e o valor imanente, não transcendente, do discurso produzido.

A idade média historicamente foi marcada pela decadência das cidades e deterioramento dos campos. É o momento das invasões, da peste e da mortalidade precoce. Em tal cenário foi necessária a formulação de um repertório simbólico para manutenção de um mínimo equilíbrio existencial em relação ao caos instaurado. Constituíram-se condições 
para o surgimento de uma visão simbólica, tornando as coisas signos de significações diversas, imatéricas, espirituais, que permitiam a fuga dessa realidade.

O homem nordestino sem erudição, fortemente moldado pelas severas regras ambientais, e por convenções sociais espiritualistas, bem como uma vida urbana pouco abastada também foi posto em papel sugestionável. Seu fazer poético (entende-se aqui em sentido amplo) fundado sob o signo do fantástico, concentra-se na explicação e relação com o mundo o qual habita, porém não o compreende de maneira lógica. A xilogravura, como parte da poética literária nordestina, torna-se tautologia do texto escrito, transcendendo seu estatuto gráfico e recontando a história ali gravada, cativando leitores de menor fluência cultural. Além de subverter a condição estabelecida por uma sociedade desigual, que priva o acesso aos meios de comunicação escritos, essa xilogravura possui função originária instigadora da visualidade e da oralidade. A imagem cordelística muitas vezes serviu e serve como instrução. Ao citar Wind, Hansen (2011) afirma que não há interesse em se repetir o que é simples, nem duplicar o complicado. Uma imagem ao duplicar um pensamento seria supérflua ou perturbadora. Se um pensamento é complicado e de difícil compreensão, necessita ser vinculado a uma imagem límpida da qual resulta-se em tautologia simplificada. Porém João Adolfo Hansen também problematiza a simplicidade das idéias ou mensagens. Explica, então, que a representação de idéias simples por ricas figurações podem ajudar a dissimular sua nudez, remetendo a alegoria assim pensada a Platão como artifício sofístico ou alegoria retórica.

Orlando Fonseca (1997) afirma que Alegoria é, paradoxalmente, ocultamento de contradições e ambiguidades que lhe dão existência. Por essa razão, o texto deve ser lido contextualmente, não de modo auto-afirmativo nem auto-legitimador do processo histórico de que é resultante, mas de maneira dialógica que supere ambos. Por ser um corpo tão fragmentado é providencial, dialeticamente, determinar um conceito aglutinador de todos esses elementos. Também afirma a respeito de metáfora expandida, como também pode ser chamada a alegroria:

Como figuração poética, a alegoria verbal insere-se na forma de metáfora continuada. O seu plano de expressão é constituído por outro discurso, o texto manifestante, que pode ser lido e tomado como coerente pela sua articulação sintagmática. Mas a sua ideologia está condicionada contextualmente pelos pressupostos implícitos na cultura. (FONSECA, 1997, p. 103)

A leitura alegórica possibilitada pela imagética xilográfica nordestina, como descendente de contexto medieval, está intrínseca ao pensamento da antiguidade oriental e Greco-romana, que fornece a matéria para interpretação. Unindo paganismo e cristianismo em uma forma inteiriça. A alegoria iconoclasta do cordel, rica em sóis, estrelas mágicas, luas cheias que tornam o homem sertanejo um lobisomem, também justifica-se através de seu misticismo e do misticismo da cultura na qual foi gerada. Tem capacidade de transpor a vida humana para um plano abstrato das simpatias e antipatias da alma do mundo, como disse 
Hansen (2011), fazendo com que as personagens narradas e ilustradas se tornem metáforas cósmicas, universais. Assim, o cordel torna-se um conjunto de signos análogos que estabelecem relações entre coisas próximas e distantes, entre aspectos exibidos e aspectos ocultos. É em seu conjunto, uma ação que formula objetos visíveis referentes a forças invisíveis.

O grotesco medieval também resurge como ponto típico a ser abordado nas imagens alegóricas das xilogravuras de cordel. As deformações físicas, marcas da vida sofrida do sertanejo e das misérias da carnalidade aparecem nas personagens. Feiúra e beleza ganham entonação romântica e maniqueísta. A beleza é característica das jovens donzelas e outros personagens bons enquanto a feiúra sempre metaforiza a maldade. Porém o enredo cordelístico não existe sem essa estrutura dicotômica. É na feiúra que habitam maior parte dos seres imaginários e mitológicos nordestinos: demônios, fantasmas, serpentes de várias cabeças etc. Ponzio (2013) afirma que a linguagem popular do corpo grotesco é rica em termos e expressões que se referem às partes que mais se comunicam com outros corpos e entre o corpo e o mundo: escrecências e orifícios (órgãos genitais, nádegas, ânus, barriga, nariz etc.) jogam na linguagem do corpo grotesco um papel primordial. Ponzio nessa mesma linha de pensamento retoma a idéia bakhtiniana de interacionismo entre os corpos, ao menos bicorporal. Esse corpo grotesco é relegado à vida cotidiana intima ou então é banido de determinadas classes sociais transformando-se em injúrias, xingamentos, palavrões e tem papel central na comicidade popular.

Pode-se comparar a imagética, vez ou outra, chula dos autores de cordel a estética de François Rabelais, carismático escritor renascentista, herdeiro de influências culturais medievais. Rabelais foi grande crítico da sociedade de sua época. Ao desejar dar forma e retratar poeticamente seus contemporâneos, tornou-se famoso pela imagética de suas obras cômicas. Confeccionou textos retratando seu mundo excessivo e exuberante, inspirado, como no cordel, em lendas populares, farsas e contos clássicos. Um mundo cheio de vícios e corrupções aos costumes. Bakhtin (1993) ressalta a condição frívola, festiva e muitas vezes grotesca, presente na construção poética de Rabelais, a chamada "carnavalização". Tanto os autores cordelistas como os artistas medievais, unificam imagens textuais com capacidade universalizadora popular a individualidade e detalhamentos que só podem ocorrer através de uma visão profunda e detalhada de suas épocas.

\section{Considerações finais}

A representação gráfica simples e muitas vezes ingênua e os textos versificados do cordel são herança da idade média, cristalizados pela igreja em forma de herança cultural, quando a mesma usava da iconoclastia maniqueísta cristã (seja ela pictórica, escultórica ou gráfica) para arrebanhar fiéis, tornando-a fonte de arrebatamento e para fazer tementes os 
iletrados. A xilogravura (cumprindo papel de iluminura) e o cancioneiro (remetendo-nos as caóticas feiras e salões festivos medievais), como partes da poética literária nordestina, tornam-se tautologia do texto escrito. Transcende seu estatuto gráfico e musical recontando a história ali gravada, cativando e instruindo leitores de menor fluência cultural. Além de subverter a condição estabelecida por uma sociedade desigual, que priva o acesso aos meios de comunicação escritos. O cordel é uma alegoria que constitui retrato de duas grandes sociedades separadas no tempo-espaço (ibérica e brasileira). Cristalizando e remontando características culturais, espirituais, políticas e medievais que, de forma cíclica e quase espelhada, através da colonização e miscigenação étnica reapareceram no nordeste do Brasil. No entanto, mesmo fortemente atrelada a uma herança cultural secular, permite-se tornar-se fluida como linguagem. Molda-se a seus leitores pelo artifício da tautologia. Atravessa o tempo como livreto, prosa, verso, imagem, voz, música, performance. Essa tautologia possui função originária instigadora da visualidade e da oralidade que pode ser classificada como mista. Uma oralidade marcada pela coexistência com a cultura imagética e escrita. Essa mestiçagem de linguagens torna-se tão profunda que não mais existe uma nitidez acabando por fundir-se e confundir-se. O conjunto metafórico dessa tautologia organiza-se a partir da força poética do cordel como expressão popular gerando-se alegorias alimentadas pelo complexo contexto sertanejo e seu misticismo. Fazendo ligações entre o mundo matérico e o espiritual. Revelando assim, a potência criadora, transgressora e fluída dessa linguagem essencialmente popular que alegoricamente associa mito e sentido de atualidade em um panorama contemporâneo.

\section{REFERÊNCIAS}

ABREU, Márcia. Histórias de cordéis e folhetos. Campinas: Mercado as Letras, 1999.

BAKHTIN, Mikhail: A Cultura Popular na Idade Média e no Renascimento. Brasília: Editora da Universidade de Brasília, 1993.

BURKE, Peter. Cultura Popular na Idade Moderna. São Paulo: Editora SchwarczLtda, 1989.

FONSECA, Orlando. Na vertigem da alegoria: militância poética de Ferreira Gullar. Santa Maria: Editora UFSM, 1997. 
GALVÃO, Ana Maria de Oliveira. Cordel: leitores e ouvintes. Belo Horizonte: Autêntica, 2001.

HAURÉLIO, Marco. Breve História da Literatura de Cordel. São Paulo: Claridade, 2010.

HASEN, João Adolfo. Alegoria: construção e interpretação da metáfora. São Paulo: Editora Hedra, 2007.

PONZIO, Augusto: No círculo com Mikhail Bakhtin. São Carlos: Pedro \& João Editora, 2013.

SANTOS, IdeletteMuzart-Fonseca dos. Memória das vozes: cantoria, romanceiro e cordel. Salvador: Fundação Cultural do Estado da Bahia, 2006.

STAM, Robert.Bakhtin: da Teoria literária à Cultura de Massa. São Paulo: Editora àtica, 1992.

TERRA, Ruth Brito Lêmos. Memórias de lutas: Literatura de folhetos do Nordeste 18931930. São Paulo: Global Editora, 1983.

\section{Apêndice}

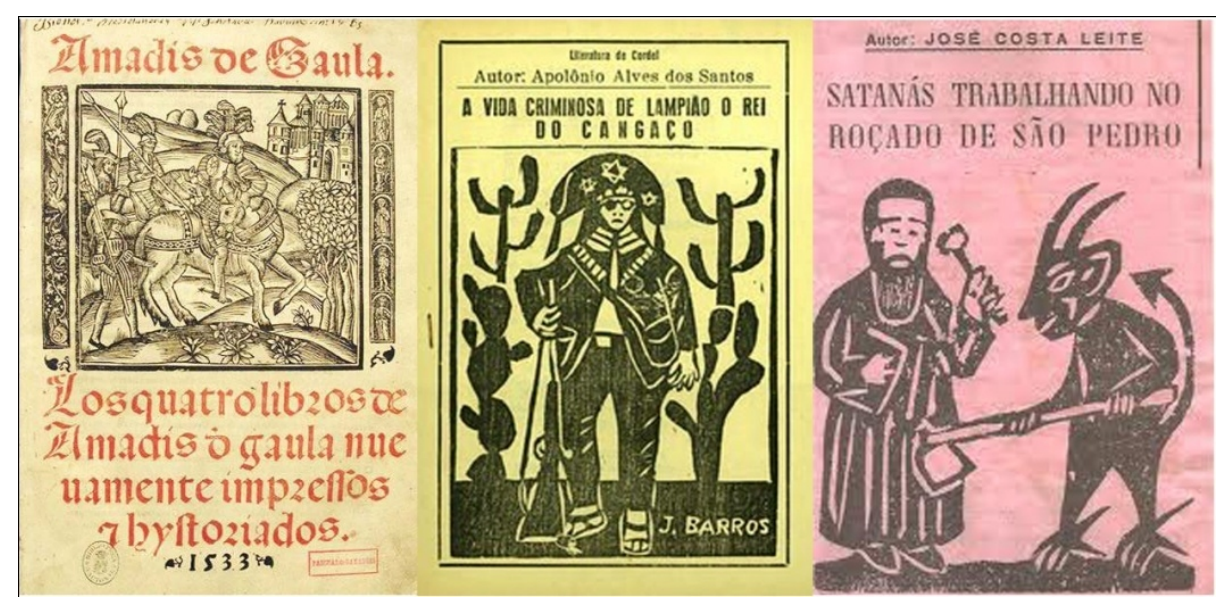

Figura 1 - Da esquerda para direita: capa datada de 1508 da obra Amadis de Gaula, principal 
obra do romance de cavalaria ibérico. Capa do cordel A Vida de Lampião o rei do cangaço, de Apolônio Alves dos santos e gravura de J. Barros. Capa do cordel Satanás Trabalhando no Roçado de São Pedro, de José da costa leite (também autor da gravura).

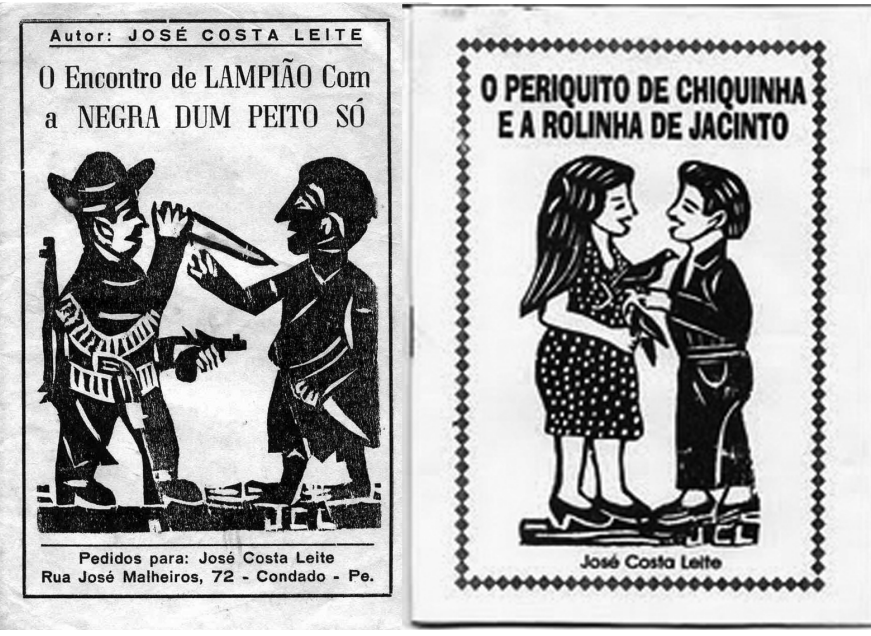

Figura 2 - Da esquerda para a direita: capas dos cordéis Encontro de Lampião com a Negra dum Peito Só e $O$ Periquito de Chiquinha e a Rolinha de Jacinto, de José Costa Leite (também autor das gravuras). 